\title{
STUDY OF MECHANICAL PROPERTIES OF BANANA-COIR HYBRID COMPOSITE USING EXPERIMENTAL AND FEM TECHNIQUES
}

\author{
T. Hariprasad ${ }^{1,}$ G. Dharmalingam ${ }^{2}$ and P. Praveen Raj $^{3}$ \\ ${ }^{1}$ Department of Mechanical Engineering, Sree Vidyanikethan Engineering College \\ Tirupati, Andhra Pradesh - 517102 \\ Email: thprasads@gmail.com \\ ${ }^{2}$ Department of ME SRM University,Chennai \\ ${ }^{3}$ Department of ME, Thanthai Periyar Government Institute of Technology \\ Bagayam, Vellore, Tamil Nadu, India-632002
}

\begin{abstract}
The use of natural fibers as reinforcement in polymers has gained importance in recent years due to their eco-friendly nature. Thus, an investigation has been undertaken on banana-coir, which is a natural fiber abundantly available in India. Natural fibers are not only strong and lightweight, but also relatively very cheap. Composite plates were prepared with resin $392 \mathrm{~g}$, coir $54 \mathrm{~g}$, and banana $69 \mathrm{~g}$. The purpose of this work is to establish the tensile, flexural, and impact properties of banana-coir reinforced composite materials with a thermo set for treated and untreated fibers. The resin used was epoxy (EP306). The tensile and impact tests showed that treated banana-coir epoxy hybrid composites have higher tensile strength and impact strength than untreated composites. However, untreated fiber composites have greater flexural strength than the treated fiber composites. The finite element analysis (FEA) software ANSYS has been employed successfully to evaluate the properties. The stresses at the interface of the banana-coir and matrix, induced by the different loading conditions, were applied to predict the tensile, impact, and flexural properties by using the FEA models. The model output was compared with the experimental results and found to be close. This analysis is useful for realizing the advantages of hybrid fiber reinforced composites in structural applications and for identifying where the stresses are critical and damage the interface under varying loading conditions.
\end{abstract}

Keywords: Banana-fiber; coir-fiber; tensile; flexural; impact; FEA model.

\section{INTRODUCTION}

Usually, fiber reinforcement is done to obtain high strength and high modulus. Hence, it is necessary for the fiber to possess a higher modulus than the matrix material, such that the load is transferred to the fiber from the matrix more effectively. Fiber reinforced composites are popularly, and are used in many industrial applications because of their high specific strength and stiffness. Nowadays, natural fibers are replacing traditional manmade fibers as reinforcements because they have several advantages (Wallenberg \& Weston, 2004). A number of investigations have been conducted on several types of natural fibers, such as kenaf, hemp, flax, bamboo, and jute, to study the effects of these fibers on the mechanical properties of composite materials (Gowda, Naidu, \& Chhaya, 1999; Umar et al., 2012; Ibrahim, Sapuan, \& Faieza, 2012; Hardinnawirda \& SitiRabiatull Aisha, 2012; Bhaskar \& Sharief, 2012). Of these, banana and coir are gaining more importance. The main chemical constituents of banana fibers are 
hemicellulose and lignin. Hemicellulose and cellulose are present in the form of holocellulose in banana fibers, which contributes more than $70 \%$ of the total chemical constituent present in banana fiber. Another important chemical constituent present in banana fiber is lignin. Lignin acts as a binder for the cellulose fibers and behaves as an energy storage system. Coir is an abundant, versatile, renewable, cheap, and biodegradable lignocellulose fiber used for making a wide variety of products. Coir has also been tested as a filler or reinforcement in different composite materials. Coconut coir is the most interesting product because it has the lowest thermal conductivity and bulk density (Umar, Zainudin, \& Sapuan, 2012; Prasanna \& Subbaiah, 2011). Recently, multicomponent composite materials comprising two or more families of fibers have been attracting the attention of researchers. This is because the use of one type of fiber alone has proved inadequate in tackling satisfactorily all the technical and economic problems presented when making fiber reinforced composites. These types of composites introduce additional degrees of compositional freedom, providing yet another dimension to the potential versatility of fiber-reinforced composite materials. The ultimate strength of the system is the stress level at which the elongation of the system reaches the ultimate elongation of the fiber family. Attempts have been made by other researchers to prepare hybrid composites of natural fiber and synthetic fiber to improve the mechanical properties of the composites.

An investigation was performed using coir, banana-fiber-filled composites based on high-density polyethylene (HDPE)/Nylon-6 blends. It was studied for its properties (Haydaruzzaman, Khan, Hossain, Khan, \& Khan, 2010; Khanam, Ramachandra Reddy, Raghu, \& Venkata, 2010). The hybrid composites of coir/silk unsaturated-polyesterbased hybrid composites were studied for the effects of fiber length on the mechanical behavior of coir-fiber-reinforced epoxy composites (Liu, Wu, \& Zhang, 2009). Variations in the tensile and impact properties of banana-fiber-reinforced polyester composites, caused by the addition of glass fiber, have been analyzed (Maleque, Belal, \& Sapuan, 2007; Adebisi, Maleque, \& Rahman, 2011; Jeffrey, Tarlochan, \& Rahman, 2011). Coir-yarn-reinforced polypropylene (PP)-based unidirectional composites were prepared by compression molding. Coir yarn content in the composite was optimized and 20\% yarn content showed higher mechanical properties. Jute yarns (20\% to 100\%) were incorporated into the coir-based composites (Bachtiar, Sapuan, \& Hamdan, 2010; Pothan, Thomas, \& George, 2012). Banana-fiber-reinforced plastic composites having fiber length of $30 \mathrm{~mm}$ and a fiber content of $40 \mathrm{vol} \%$ demonstrated the maximum tensile strength. The highest values of tensile strength were obtained for composite samples with a mixture of banana and glass fibers prepared by interleaving layers of banana fiber and glass fiber (Haydaruzzaman et al., 2007). A lightweight composite material was prepared using banana empty fruit bunch fibers as reinforcement in a polyester resin matrix and its mechanical properties studied (Srinivasababu, Rao, \& Suresh Kumar, 2009). There has been much research on different combinations of natural fiber. However, none has reported on a banana-coir combination epoxy composite, although each material individually has attracted significant attraction. Therefore, the present work has been undertaken to develop a polymer matrix composite (epoxy resin) using banana-coir fibers as reinforcement and to study its mechanical properties. The composites were prepared with $30 \%$ volume fraction of fibers. (Kulkarni, Satyanarayana, Rohatgi, \& Kalyanivijayan, 1984). 


\section{MATERIALS AND METHODS}

\section{Banana Fibers}

The epoxy composite reinforced with pseudo-stem banana woven fiber was prepared by the hand lay-up method. The fibers were extracted from banana stems by hand and dried in sunlight for 12 hours until all the moisture was removed. The woven banana fibers used for the study are shown in Figure 1.
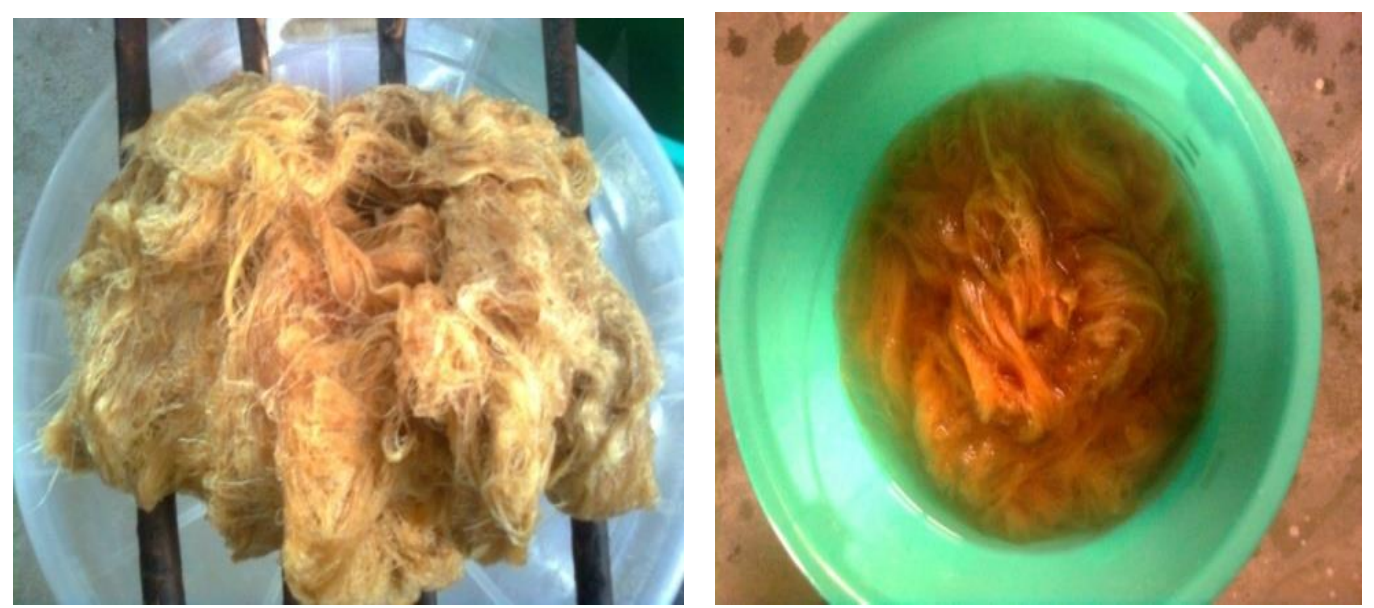

a) Banana woven fiber

b) Banana fiber immersed in $6 \% \mathrm{NaOH}$ solution

Figure 1. Banana woven fiber.

\section{Coir Fiber}

Coir is a coarse fiber extracted from the fibrous outer shell of a coconut. The individual fiber cells are narrow and hollow with thick walls made of cellulose. Traditionally, it has been used in tropical regions of Asia, Africa, and South America in a variety of simple item, such as rugs, couch and mattress stuffing, as well as gardening pots. The coir fibers used for the study are shown in Figure 2.

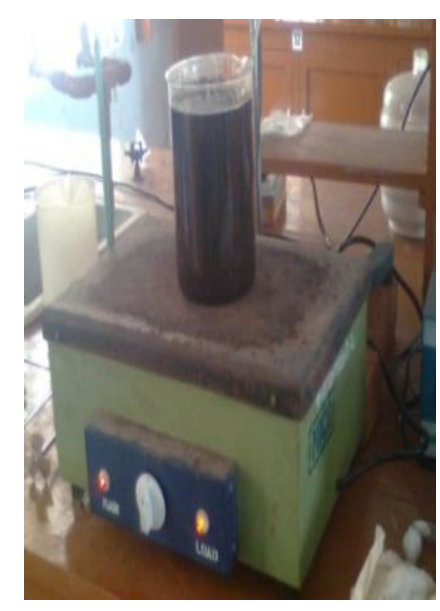

(a) Coir fiber treated in heater

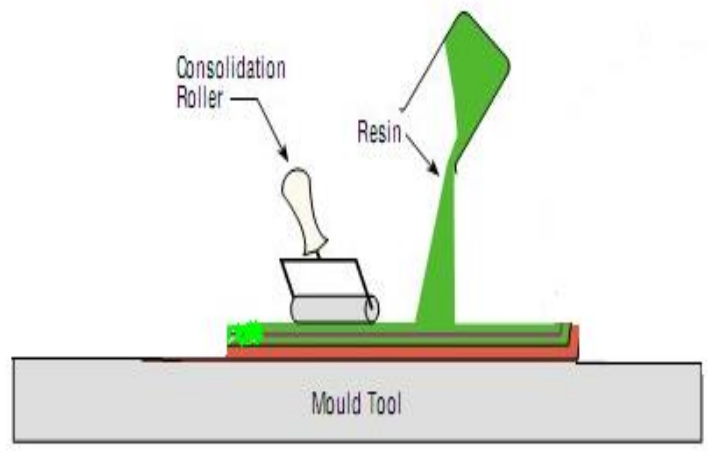

(b) Hand layup method

Figure 2. Experimental set up. 


\section{Epoxy Resin}

Epoxy or polyepoxide is a thermosetting polymer formed from the reaction of an epoxide "resin" with a polyamine "hardener". Epoxy has a wide range of applications, including fiber-reinforced plastic materials and general-purpose adhesives. The resin consists of monomers or short-chain polymers with an epoxide group at either end. Most common epoxy resins are produced from a reaction between epichlorohydrin and bisphenol-A, although the latter may be replaced by similar chemicals. The hardener consists of polyamine monomers, for example, Triethylenetetramine (TETA). When these compounds are mixed together, the amine groups react with the epoxide groups to form a covalent bond. Each NH group can react with an epoxide group, such that the resulting polymer is heavily cross-linked and thus, becomes rigid and strong. The process of polymerization is called "curing", and can be controlled through temperature and the choice of resin and hardener compounds; the process can take minutes to hours. Some formulations benefit from heating during the curing period, whereas others simply require time and ambient temperatures. Industrial Specifications and Notifications of Materials (M/s Roto Polymers., Chennai.) are shown in Table 1.

Table 1. Properties of materials.

\begin{tabular}{lccccc}
\hline & $\begin{array}{c}\text { Company } \\
\text { code }\end{array}$ & Color & $\begin{array}{c}\text { Specific } \\
\text { gravity }\end{array}$ & Viscosity & $\begin{array}{c}\text { Epoxy } \\
\text { Value }\end{array}$ \\
\hline $\begin{array}{l}\text { Diglycidyl Ether } \\
\text { of Bisphenol-A }\end{array}$ & EP 306 & $\begin{array}{l}\text { Transparent, } \\
\text { sticky liquid }\end{array}$ & $\begin{array}{c}1.14-1.19 \\
\text { @ } 25^{\circ} \mathrm{C}\end{array}$ & $\begin{array}{c}9500-12500 \\
\mathrm{cps}\end{array}$ & $5-5.5$ \\
& & & @ $25^{\circ} \mathrm{C}$ & \\
$\begin{array}{l}\text { Di Ethyl Tetra } \\
\text { Amine }\end{array}$ & EH 758 & $\begin{array}{c}\text { Transparent, } \\
\text { liquid }\end{array}$ & $\begin{array}{c}0.95-1.05 \\
\text { @ } 25^{\circ} \mathrm{C}\end{array}$ & $\begin{array}{c}20-50 \mathrm{cps} \\
\text { @ 25 }{ }^{\circ} \mathrm{C}\end{array}$ & -- \\
\hline
\end{tabular}

\section{Chemical Treatment}

Alkali treatment of natural fibers, also called mercerization, is the common method to produce high-quality fibers. Mercerization leads to fibrillation, which causes the breakdown of the composite fiber bundle into smaller fibers. Mercerization reduces fiber diameter, thereby increasing the aspect ratio, which leads to the development of a rough surface topography that results in better fiber-matrix interface adhesion and an increase in mechanical properties. Moreover, mercerization increases the number of possible reactive sites and allows better fiber wetting. Mercerization has an effect on the chemical composition of the flax fibers and degree of polymerization. The degree of polymerization is the number of repeat units in an average polymer chain at time $t$ in a polymerization reaction. The length is in monomer units. The degree of polymerization is a measure of molecular weight and molecular orientation of the cellulose crystallites due to cementing substances, such as lignin and hemicelluloses, which are removed during the mercerization process. As a result, mercerization had a long-lasting effect on the mechanical properties of flax fibers; mainly on fiber strength and stiffness. 


\section{Properties of Hardener}

In the present work, the hardener (EH758) has been used. The properties of the hardener are shown in Table 1.

\section{Banana Fiber Treatment}

Banana fibers were immersed in $6 \% \mathrm{NaOH}$ solution for two hours at room temperature, as shown in Figure 1(b). Following the alkali treatment, the fibers were washed thoroughly by immersion in water tanks, followed by running water. The material was then filtered and dried at $80{ }^{\circ} \mathrm{C}$ for 24 hours. The banana fiber immersed in $6 \% \mathrm{NaOH}$ solution. The banana fibers obtained after the final washing are shown in Figure 1(a).

\section{Coconut Fiber Treatment}

Prior to treatment, all fibers were pre-washed with large amounts of distilled water and dried at $50{ }^{\circ} \mathrm{C}$ until constant weight. The mercerization process consisted of immersing the coir fibers $(200 \mathrm{~g})$ in a $10 \%(\mathrm{w} / \mathrm{v}) \mathrm{NaOH}$ aqueous solution $(2 \mathrm{~L})$ for three hours at $70{ }^{\circ} \mathrm{C}$ with occasional shaking, followed by repeated washing with distilled water to remove any absorbed alkali. Then, the fibers were dried in sunlight. The coir fiber was treated in a heater, as shown in Figure 2(a).

\section{Fabrication of Composites}

There is a wide variety of fiber-reinforced plastic processes. The choice of process depends on many factors, such as type of reinforcement and matrix materials, size, shape, quantity, and cost. There are many specialized processes available, but only the most commonly used commercial process, hand lay-up, has been used here in the preparation of the composites. The experimental setups are shown in Figure 2(b). A weight press was needed for the hand lay-up method. The base plate was cleared of rust by scrubbing with an abrasive paper. Then, the surface was allowed to dry after cleaning it with a thinner solution. After drying, the surface was coated with silicone gel. The surface was given a few minutes to set before the mold lay-up. The company codes for the epoxy semi-polymerized resin and the Hardener/Curing agent were EP-306 and EH758, respectively. They were mixed in the proportion of 10:1 (EP-306 and EP-758). The curing time or the pot life, which is how it is usually denoted on laboratory charts, was 20 minutes once mixed. Care was taken that the resin did not cure in the curing pot itself. A constant watch was maintained over the blend in the pot with the aid of a stopwatch.

A plate of dimensions $300 \times 300 \times 8 \mathrm{~mm}$ was fabricated by this process. First, the epoxy-banana-coir composite was fabricated. The matrix material was poured slowly into the mold to avoid trapping air. The mixture was left for 2 minutes until it became a little tacky. After that, the banana fiber ply was laid unidirectionally on the matrix layer, which was covered by another layer of matrix poured slowly onto the surface of the fiber ply. A small pressure was applied by using a roller to distribute the matrix material and to avoid the formation of voids. Then, chopped coir fibers (30-50 $\mathrm{mm}$ ) were laid on the matrix layer. The banana-coir-banana-coir-banana layer plate was fabricated similarly. The setup was cured under the loaded condition of $25 \mathrm{Kg}$ for about 24 hours. 


\section{MATERIAL TESTING}

\section{Tensile Test}

A tensile test, also known as a tension test, is probably the most fundamental type of mechanical test performed on any material. Tensile tests are simple, relatively inexpensive, and fully standardized. As the material is being pulled, we can establish its strength together with how much it will elongate. The point of failure of the material is of significant interest and it is typically called its "Ultimate Tensile Strength" (UTS). For some materials (e.g., metals and plastics), the departure from the linear elastic region cannot be identified easily. Therefore, an offset method is allowed to determine the yield strength of the tested material. These methods are discussed in ASTM E8 (metals) and D638 (plastics). An offset is specified as a percentage of strain (for metals, it is usually $0.2 \%$ from E8, and sometimes for plastics a value of $2 \%$ is used). The stress that is determined from the intersection point, when the line of the linear elastic region (with slope equal to the Modulus of Elasticity) is drawn from the offset, becomes the Yield Strength by the offset method. The tensile curves of some materials do not have a very well defined linear region. In these cases, ASTM Standard D638 provides for alternative methods for determining the modulus of a material, in addition to the Young's modulus. These alternatives are the secant modulus and the tangent modulus. One of the properties that can be determined about a material is its UTS. This is the maximum load the specimen can sustain during the test. The UTS may or may not equate to the strength at break. This all depends on the type of material being tested: brittle, ductile, or a substance that even exhibits both properties. Sometimes, a material may be ductile when tested in a lab, but when placed in service and exposed to extreme cold temperatures, it may make a transition to brittle behavior. The tensile test was conducted in a UTM Lloyd LR100K Testing Machine. The $10 \mathrm{kN}$ (2000 lbf) twocolumn LR100K incorporates the latest technology and quality engineering. The material was loaded in the machine and the load applied at an increasing rate until it reached the maximum tensile load. When the load reached the maximum tensile load, the sample broke. The load at this point is used to calculate the maximum tensile strength of the composite material. According to the ASTM D 638 standards, five test specimens were made, as shown in Figure 3(a).

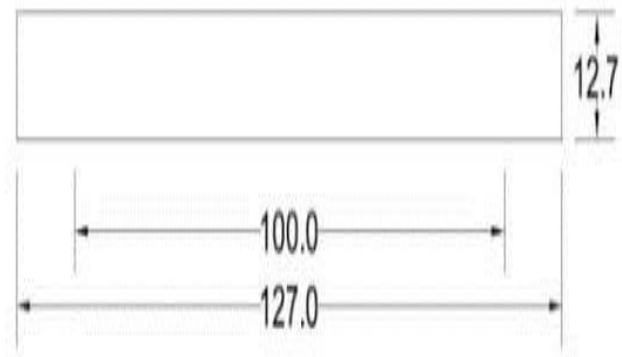

(a) ASTM D638 standard specimen 1 (treated)

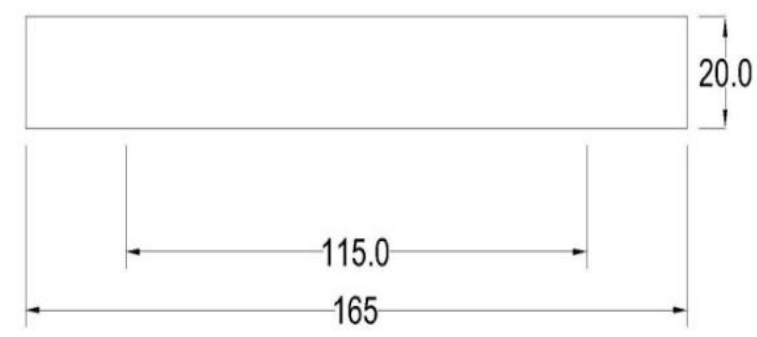

(b) ASTM D790 standard specimen 2 (untreated)

Figure 3. Specimens used. 


\section{Flexural Test}

Flexural strength, also known as the modulus of rupture, bend strength, or fracture strength, is a mechanical parameter for brittle materials, which is defined as the ability of the material to resist deformation under a load. The transverse bending test is the one employed most frequently, in which a rod-shaped specimen, having either a circular or a rectangular cross section, is bent until fracture by using a three-point flexural test technique. The flexural strength represents the highest stress experienced within the material at its moment of rupture. It is measured in terms of stress. The flexural strength would be the same as the direct tensile strength (see UTS) if the material were homogeneous. In fact, most materials have small or large defects, which act to concentrate the stresses locally, effectively causing localized weaknesses. When a material is bent, only the extreme fibers are at the largest stress; therefore, if those fibers are free from defects, the flexural strength will be controlled by the strength of those intact fibers. However, if the same material is subjected to direct tension, then all the fibers in the material are at the same stress and failure will initiate when the weakest fiber reaches its limiting tensile stress. Therefore, it is common for flexural strengths to be higher than direct tensile strengths for the same material. Conversely, a homogeneous material with defects only on it surfaces (e.g., due to scratches) might have a higher direct tensile strength than flexural strength.

In mechanics, the flexural modulus is the ratio of stress to strain in flexural deformation, or the tendency for a material to bend. It is determined from the slope of a stress-strain curve produced by a flexural test (such as the ASTM D 790) and uses units of force per area. It is an intensive property. The flexural modulus determined by a three-point deflection test of a beam is given by Eq. (1)

$$
E(\text { bend })=\frac{L^{3} F}{4 w h^{3} d}
$$

where $w$ and $h$ are the width and height of the beam, $L$ is the distance between the two outer supports, and $d$ is the deflection due to load $F$ applied at the middle of the beam. According to the ASTM D 790 standards, five test specimens were made, as shown in Figure 3(b).

\section{Impact Test}

The impact test is designed to give information on how a specimen of a known material will respond to a stress applied suddenly, e.g., shock. The test ascertains whether the material is tough or brittle. A notched test piece is normally employed and the two methods in general use are the Izod and the Charpy test. The result is usually reported as the energy in ft.lbs. or KJ required to fracture the test piece. Molded-in stresses, polymer orientation, weak spots (e.g., weld lines or gate areas), and part geometry will affect the impact performance. Impact properties also change when additives, e.g., coloring agents, are added to plastics. The Charpy impact test, also known as the Charpy v-notch test, is a standardized high-strain-rate test, which determines the amount of energy absorbed by a material during fracture. This absorbed energy is a measure of the toughness of a given material and acts as a tool to study temperature-dependent brittle-ductile transitions. It is applied widely in industry, because it is easy to prepare and conduct, and because the results can be obtained quickly and cheaply. However, a major disadvantage is that all results are only comparative. The test specimen size was prepared as per the standard IS 867. 


\section{FINITE ELEMENT ANALYSIS}

To study the elastic behavior of plastics and to predict some of the resulting important mechanical properties, a finite-element analysis (FEA) was carried out. Although most of these properties can be obtained through experimentation, the elastic-plastic transition behavior in plastics is not easy to study under experimental conditions; hence, the need for theoretical modeling. In addition to validating the experimental findings, the theoretical prediction of these properties can shorten the cycle time for determining the optimum filler quantities that will maximize the properties of the resulting composite. A finite element model of the experimentally molded specimens was created using ANSYS 11.0 software. Preliminary results from the tensile, flexural, and impact tests indicated that the composite material was very brittle, but that it exhibited linear deformation in its elastic state. Thus, the model was developed using a SOLID 20 node186 element, using an elastic material with mechanical characteristics. Because thermosetting plastic was considered with granular additives, the behavior was uncertain. SOLID 20 node186 elements permit irregular shapes and its 20 nodes allow for any spatial orientation. Models of treated and untreated specimens were tested under different simulated loading conditions (Otieno, Tatara \& Suraparaju, 2006).

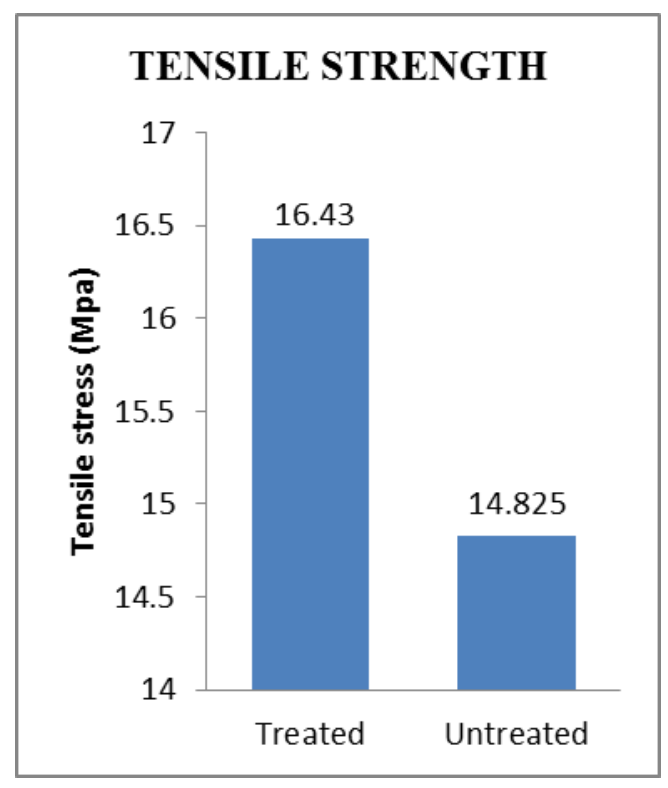

a) Tensile strength comparison

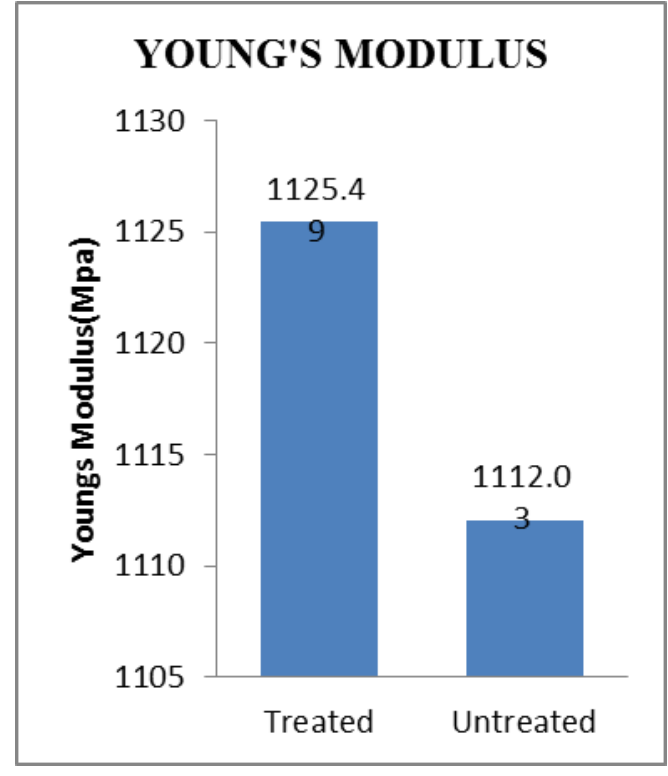

b) Young's modulus comparison

Figure 4. Comparison of tensile strength and Young's modulus

\section{RESULTS AND DISCUSSION}

\section{Tensile Test Results}

The results obtained from the tension test for the treated and untreated banana-coir composite are tabulated in Table 2. In addition, the tensile properties of the treated and untreated banana-coir epoxy composites were measured and they are tabulated in Table 2. The tensile strength of these composites was compared using the bar chart, as 
shown in Figure 4. It was found that the treated composite has greater tensile strength than the untreated composite. The tensile strengths of these materials are compared in Table 2. The values of Young's modulus were also compared using the bar chart shown in Figure 4. It was found that the treated composite has a higher Young's modulus than the untreated composite.

Table 2. Measured properties of banana-coir epoxy composite (treated and untreated).

\begin{tabular}{|c|c|c|c|c|c|c|}
\hline \multirow{7}{*}{$\begin{array}{l}\text { Treated } \\
\text { Specimen }\end{array}$} & & Trial-1 & Trial-2 & Trial-3 & & Average \\
\hline & Width (mm) & 21.1 & 19.3 & 20.1 & & - \\
\hline & Thickness (mm) & 7.1 & 7.1 & 6.8 & & - \\
\hline & $\operatorname{Max} \operatorname{load}(\mathrm{N})$ & 2760 & 2520 & 1710 & & 2330 \\
\hline & Tensile strength (MPa) & 18.4 & 18.4 & 12.5 & & 16.43 \\
\hline & Young's modulus (MPa) & 1257.9 & 1450.1 & 668.5 & & 1125.4 \\
\hline & Extension at break (mm) & 1.68 & 1.46 & 2.15 & & 1.76 \\
\hline \multirow{11}{*}{$\begin{array}{l}\text { Untreated } \\
\text { Specimen }\end{array}$} & Width (mm) & 20.1 & 18.8 & 19.0 & & 19.0 \\
\hline & Thickness (mm) & 8.7 & 8.7 & 8.5 & & 8.9 \\
\hline & Max load (kgf) & 257 & 265 & 253 & & 235 \\
\hline & Tensile strength (MPa) & 14.42 & 15.89 & 15.36 & & 13.63 \\
\hline & Young's modulus (MPa) & 1176.09 & 1427.61 & 905.84 & & 938.59 \\
\hline & Extension at break (mm) & 1.41 & 1.28 & 1.95 & & 1.67 \\
\hline & Width (mm) & 13.00 & 13.80 & 13.70 & 13.75 & - \\
\hline & Thickness (mm) & 8.60 & 7.12 & 7.02 & 7.03 & - \\
\hline & Max load (kgf) & 198 & 177 & 196 & 145 & - \\
\hline & Flexural strength (MPa) & 30.74 & 37.94 & 43.47 & 31.86 & 36.00 \\
\hline & Flexural modulus (MPa) & 3120 & 5486 & 5192 & 4954 & 4688 \\
\hline \multirow{5}{*}{$\begin{array}{l}\text { Treated } \\
\text { Specimen }\end{array}$} & Width (mm) & 12.65 & 12.12 & 12.80 & 12.70 & - \\
\hline & Thickness (mm) & 8.49 & 8.45 & 8.62 & 8.62 & - \\
\hline & $\operatorname{Max} \operatorname{load}(\mathrm{N})$ & 123 & 109 & 105 & 166 & - \\
\hline & Flexural strength $(\mathrm{MPa})$ & 20.16 & 18.95 & 16.59 & 26.38 & 20.52 \\
\hline & Flexural modulus (MPa) & 5148 & 3625 & 4609 & 6179 & 4890.25 \\
\hline
\end{tabular}

\section{Flexural Test}

The results obtained from the flexural tests for the treated and untreated banana-coir composites are shown in Table 2. The flexural properties of the untreated banana-coir epoxy hybrid composite and the treated banana-coir epoxy hybrid composite were measured and tabulated, as shown in Table 2 and the flexural strength of these composites was compared using the bar chart, as shown in Figure 5(a). The flexural strengths of these materials were compared and it was found that the untreated bananacoir epoxy composite has greater flexural strength than the treated one. The values of the Young's modulus were compared using the bar chart shown in the Figure 5(b). It was found that the treated banana-coir epoxy composite has a higher Young's modulus than the untreated banana-coir composite. 


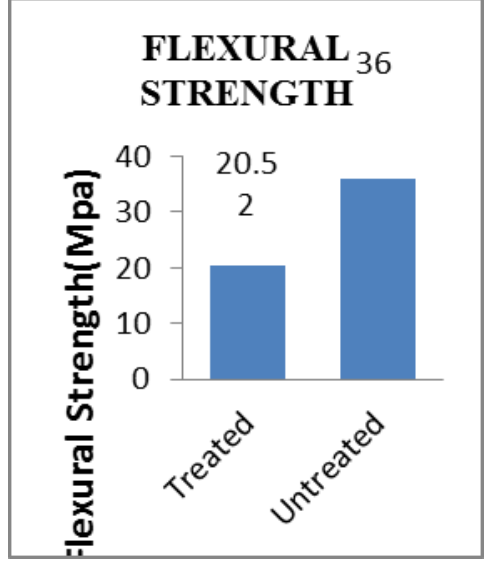

a) Flexural strength

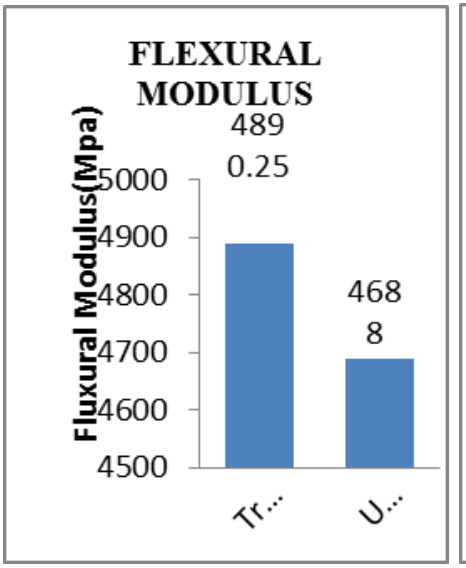

b) Flexural modulus

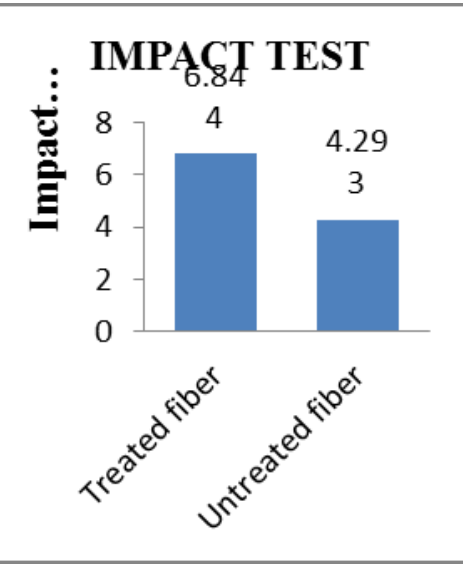

c) Impact strength

Figure 5. Comparison of flexural strength, flexural modulus, and impact strength.

\section{Impact Test}

The results obtained from the impact tests for the treated and untreated banana-coir composite are tabulated in Table 3. The impact strengths of these materials were compared using the bar chart shown in Figure 5(c). It is found that the treated bananacoir epoxy composite has greater impact strength than the untreated composite.

Table 3. Measured properties of banana-coir epoxy composite (treated and untreated).

\begin{tabular}{cccccc}
\hline $\begin{array}{c}\text { Untreated } \\
\text { Specimen }\end{array}$ & $\begin{array}{c}\text { Width } \\
(\mathrm{cm})\end{array}$ & $\begin{array}{c}\text { Thickness } \\
(\mathrm{cm})\end{array}$ & $\begin{array}{c}\text { Impact energy } \\
(\mathrm{dj})\end{array}$ & $\begin{array}{c}\text { Impact } \\
\text { strength } \\
\left(\mathrm{kg} . \mathrm{cm}^{\left.-\mathrm{cm}^{2}\right)}\right.\end{array}$ & $\begin{array}{c}\text { Average } \\
(\mathrm{N}-\mathrm{m})\end{array}$ \\
\hline Trial-1 & 1.31 & 0.66 & 4 & 4.718 & \\
Trial-2 & 1.39 & 0.69 & 3 & 3.191 & 0.36 \\
Trial-3 & 1.30 & 0.69 & 4 & 4.548 & \\
Trial-4 & 1.31 & 0.66 & 4 & 4.718 & \\
\hline Trial-1 & 1.08 & 0.85 & 5 & 5.556 & \\
Trial-2 & 1.30 & 0.85 & 10 & 9.231 & \\
Trial-3 & 1.30 & 0.86 & 6 & 4.561 & \\
Trial-4 & 1.21 & 0.84 & 11 & 8.028 & \\
\hline
\end{tabular}

\section{Simulation Results}

The simulated stress distribution of the mechanical properties of the treated and untreated banana-coir hybrid samples, under different loading conditions, was performed. The maximum stresses are averages of the values of the center elements used in the FEA. The plots of the nodal solutions showing the simulated stress distributions for the treated and untreated banana-coir hybrid samples are shown in Figures 6-8. As the results indicate, the tensile strength and impact strength of the 
treated sample increased, whereas the flexural strength decreased. Table 4 summarizes the numerical results of the predicted stress data for these specimens. By comparing the simulated and actual results, it appears that the model was accurate. The results obtained from the experimental testing and the simulations have been compared and are shown in Table 4.

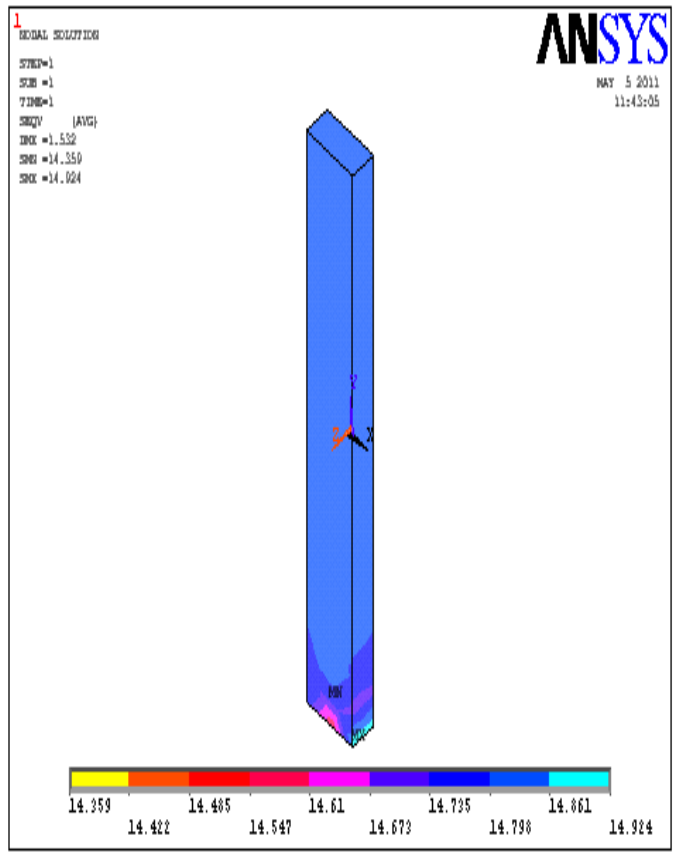

(a) untreated plate

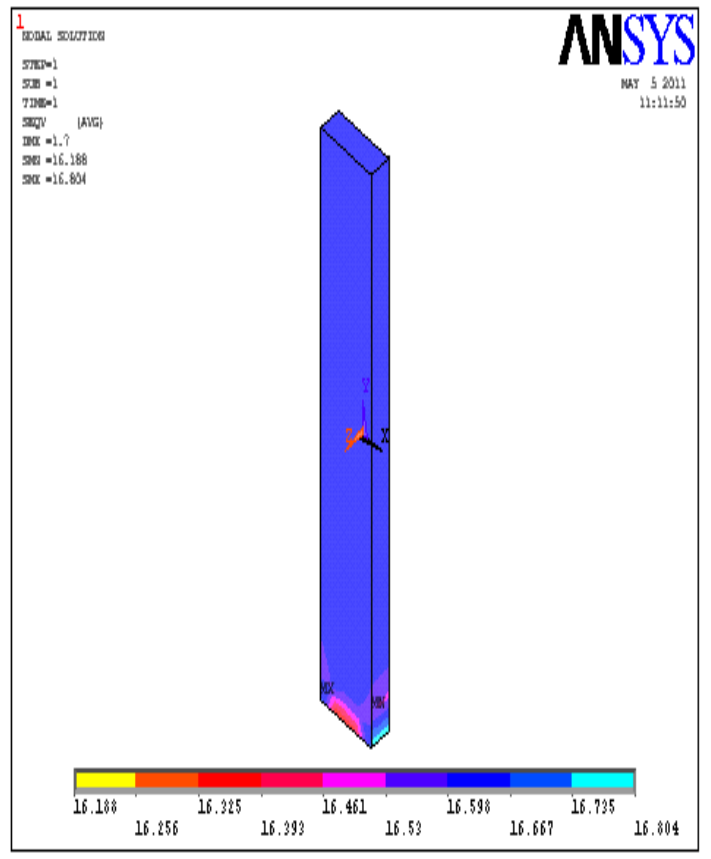

(b) treated plate

Figure 6. Tensile stress distribution.

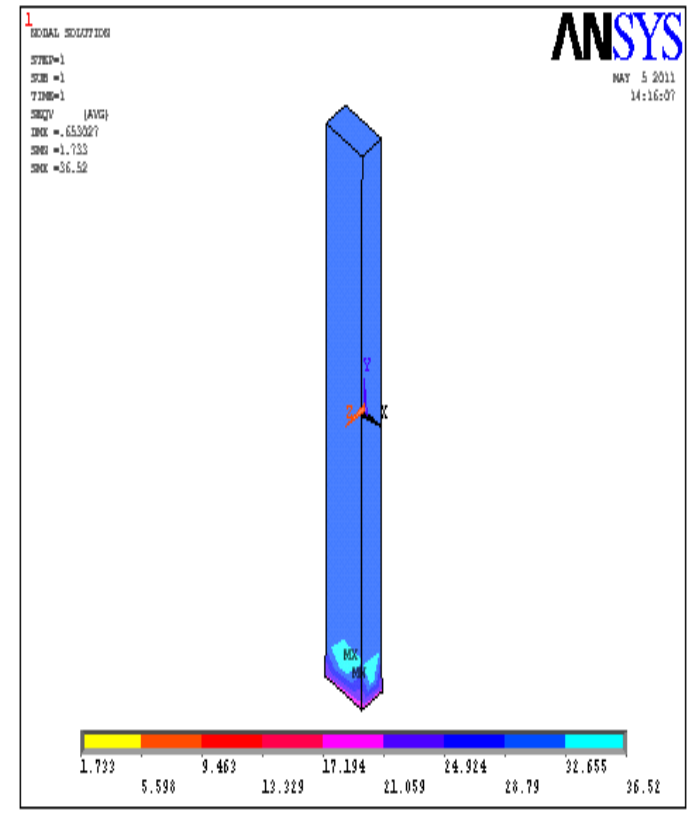

(a) untreated plate

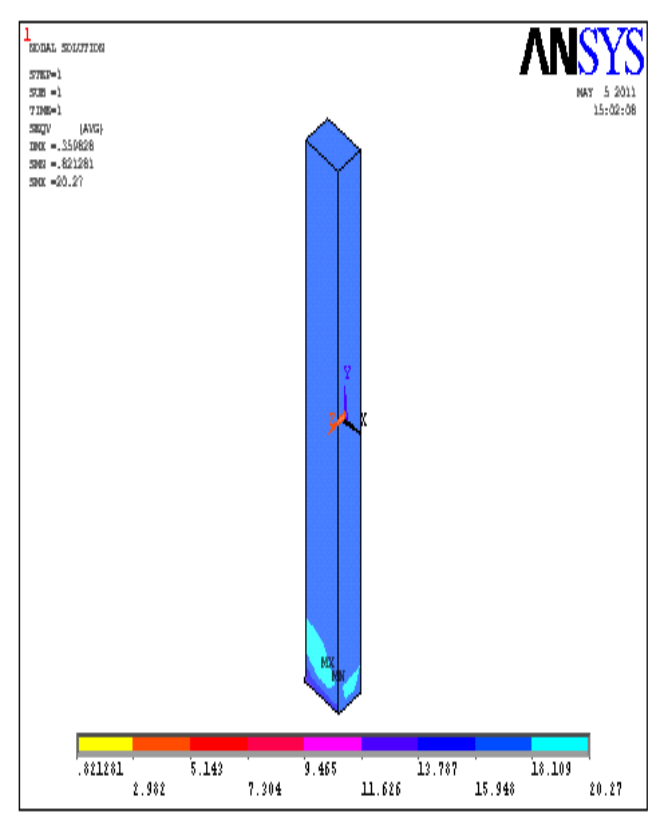

(b) treated plate

Figure 7. Flexural stress distribution. 
Table 4. Comparison of experimental and simulation results.

\begin{tabular}{clcccc}
\hline S.No & Mechanical properties & Treated & FEA Treated & Untreated & FEA Untreated \\
\hline 1 & Tensile strength $(\mathrm{MPa})$ & 16.43 & 16.80 & 14.82 & 14.92 \\
2 & Flexural strength $(\mathrm{MPa})$ & 20.52 & 20.27 & 36 & 36.52 \\
3 & Impact strength $(\mathrm{J})$ & 0.76 & 0.72 & 0.36 & 0.44 \\
\hline
\end{tabular}

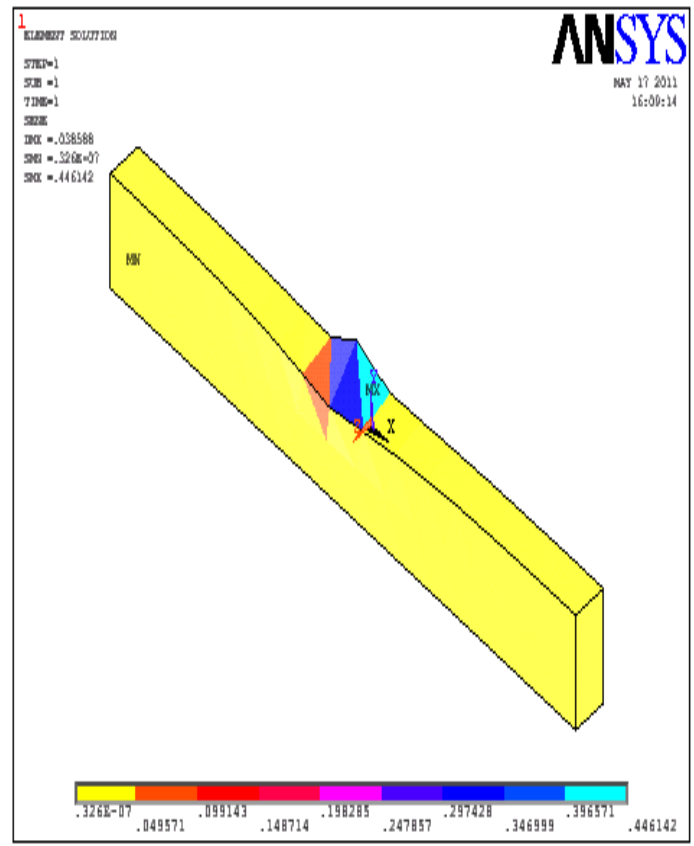

(a) untreated

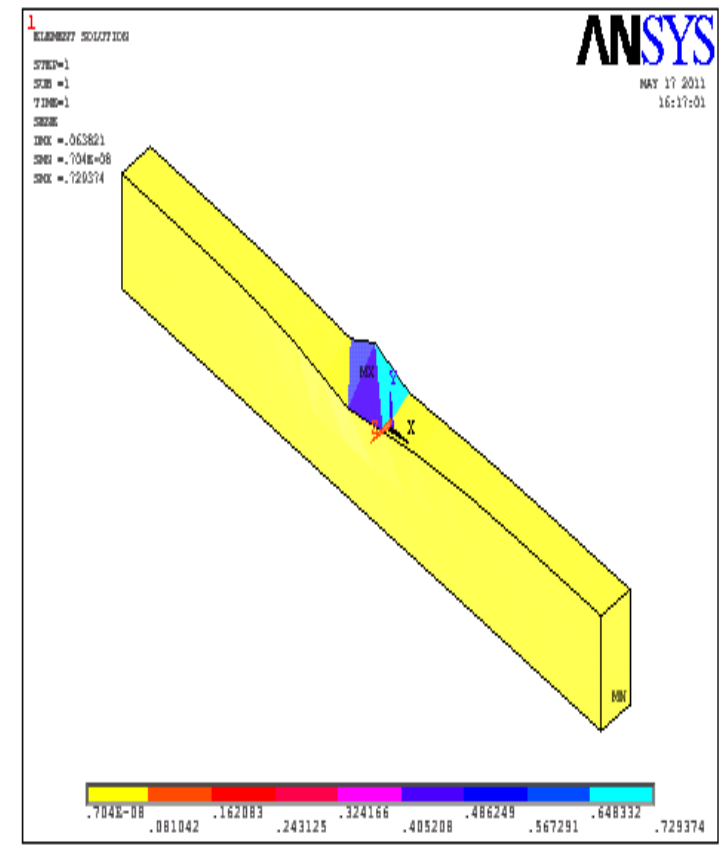

(b) treated plate

Figure 8. Impact stress distribution.

\section{CONCLUSION}

It can be concluded that an alkali-treated banana-coir epoxy hybrid composite has greater tensile strength and impact strength than an untreated banana-coir epoxy hybrid composite. However, the alkali-treated banana-coir epoxy hybrid composite has less flexural strength than the untreated banana-coir epoxy hybrid composite. The properties were improved by the alkali treatment process. In this study, the fiber weight fraction of $20 \%$ has been used. This could be increased further to establish the optimum filler volume fraction depending on the application. The simulated stress distribution for the mechanical properties of the treated and untreated banana-coir hybrid samples, under different loading conditions, was obtained. The maximum stresses are averages of the values of the center elements used in the FEA. These results indicate that the tensile strength and impact strength of the treated banana-coir fibers increased and that the flexural strength decreased. It was determined that the results of the FEA model are close to those obtained by experiment; hence, it could be used for predicting those properties required for different applications. 


\section{REFERENCES}

Adebisi, A. A., Maleque, M. A., \& Rahman, M. M. (2011). Metal matrix composite brake rotor: historical development and product life cycle analysis. International Journal of Automotive and Mechanical Engineering, 4,471-480.

Bachtiar, D., Sapuan, S. M., \& Hamdan, M. M. (2010). Flexural properties of alkaline treated sugar palm fibre reinforced epoxy composites. International Journal of Automotive and Mechanical Engineering, 1, 79-90.

Bhaskar, H. B., \& Sharief, A. (2012). Effect of solutionizing on dry sliding wear of A12024-Beryl metal matrix composite. Journal of Mechanical Engineering and Sciences, 3, 281-290.

Gowda, T. M, Naidu, A. C. B., \& Chhaya, R. (1999). Some mechanical properties of untreated jute fabric-reinforced polyester composites. Journal of Composites Part A: Applied Science and Manufacturing, 30(3), 277- 284.

Hardinnawirda, K., \& SitiRabiatull Aisha, I. (2012). Effect of rice husks as filler in polymer matrix composites. Journal of Mechanical Engineering and Sciences, 2, 181-186.

Haydaruzzaman, Khan, A. H., Hossain, M. A., Khan, M. A., \& Khan, R. A. (2010). Mechanical properties of the coir fiber reinforced polypropylene composites: effect of the incorporation of jute fiber. Journal of Composite Materials, 44(4), 401-416.

Ibrahim, M. S., Sapuan, S. M., \& Faieza, A. A. (2012). Mechanical and thermal properties of composites from unsaturated polyester filled with oil palm ash. Journal of Mechanical Engineering and Sciences, 2, 133-147.

Jeffrey, K. J. T., Tarlochan, F., \& Rahman, M. M. (2011). Residual strength of chop strand mats glass fiber/epoxy composite structures: effect of temperature and water absorption. International Journal of Automotive and Mechanical Engineering, 4, 504-519.

Khanam, P. N., Ramachandra Reddy, G., Raghu, K., \& Venkata, Naidu, S. (2010). Tensile, flexural, and compressive properties of coir/silk fiber-reinforced hybrid composites. Journal of Reinforced Plastics and Composites, 29(14), 2124-2127.

Kulkarni, A. G., Satyanarayana, K. G., Rohatgi, P. K., \& Kalyanivijayan (1983). Mechanical properties of banana fibers. Journal of Materials Science, 18, 22902296.

Liu, H., Wu, Q., \& Zhang, Q. (2009). Preparation and properties of banana fiberreinforced composites based on high density polyethylene(HDPE)/Nylon-6 blends. Bioresource Technology, 100(23), 6088-6097.

Maleque, M. A., Belal, F. Y., \& Sapuan, S. M. (2007). Mechanical properties study of pseudo-stem banana fiber reinforced epoxy composite. The Arabian Journal for Science and Engineering, 32(2B), 359-364.

Otieno, A., Tatara, R., \& Suraparaju, S. (2006). Analytical and experimental studies of properties of ethanol co product-filled plastics. Proceedings of the 2006 IJMEINTERTECH Conference, pp.1-12.

Pothan, L. A., Thomas, S., \& George, J. (2012). Tensile and impact properties of banana fiber/glassfibrehybrid polyester composites. International Committee on Composite Materials, Europe, pp. 190-200.

Prasanna, V. G., \& Subbaiah, V. K. (2011). Chemical resistance and compressive properties of banana-palmyra fibers reinforced epoxy-unsaturated polyster 
blended composites. International of Multidisciplinary Research and Advances in Engineering, 3(2), 123-130.

Srinivasababu, N., Rao, K. M. M., \& Suresh Kumar, J. (2009). Experimental determination of tensile properties of okra, sisal and banana fiber reinforced polyester composites. Indian Journal of Science and Technology, 2(7), 35-38.

Umar, A. H., Zainudin, E. S., \& Sapuan, S. M. (2012). Effect of accelerated weathering on tensile properties of kenaf reinforced high-density polyethylene composites. Journal of Mechanical Engineering and Sciences, 2, 198-205.

Wallenberg, F. T., \& Weston, N. (2004). Natural fibers, plastics and composites natural. Texas: Materials Source Book. 